\title{
Epilepsie speelt bescheiden rol als oorzaak van gedrags- problemen bij patiënten met een verstandelijke beperking
}

Op 9 oktober 2019 promoveerde Francesca Snoeijen-Schouwenaars aan de Universiteit Maastricht op haar proefschrift 'Diagnostic, Neuropsychiatric and Therapeutic considerations in Epilepsy and Intellectual Disability - medical perspectives'. In het proefschrift wordt het onderzoek naar het complexe samenspel tussen epilepsie en gedrags- en stemmingsproblemen bij mensen met een verstandelijke beperking beschreven. De verstandelijke beperking lijkt meer invloed te hebben op de gedragsproblemen dan de epilepsie.

Epilepsie is een belangrijke comorbiditeit bij mensen met een verstandelijke beperking (VB), met een gepoolde prevalentie van 22,2\% (Robertson et al., 2015). Bij mensen met een VB is de epilepsie vaker refractair en ernstiger dan bij mensen zonder een VB (Kerr et al., 20I4). Uit eerdere studies is bekend dat zowel epilepsie als een VB afzonderlijk samenhangen met het vaker optreden van neuropsychiatrische comorbiditeit. In dit proefschrift wordt een systematisch overzicht gegeven van de literatuur over de samenhang tussen epilepsie, een VB en neuropsychiatrische problemen. Er is slechts een beperkt aantal studies van voldoende methodologische kwaliteit en de uitkomsten van deze studies spreken elkaar deels tegen.

Voorzichtig zou geconcludeerd kunnen worden dat er bij patiënten met epilepsie en een VB een relatie lijkt te zijn tussen de psychiatrische problematiek en de epilepsie en dat er een verband is tussen de ernst van de epilepsie en de aanwezigheid van neuropsychiatrische comorbiditeit.

\section{Aspecten binnen de diagnostiek}

Snoeijen-Schouwenaars onderzocht voor mensen met epilepsie en een VB de opbrengst van Whole Exome Sequencing (WES). Bij 25\% van de onderzochte populatie kon alsnog een diagnose middels de WES-diagnostiek worden gesteld. Bij 40\% van de groep met een nieuw gestelde (genetische) diagnose zou de gevonden mutatie direct van invloed kun- nen zijn op de therapeutische overwegingen. De neuropsychiatrische diagnostiek werd als onderdeel van de grotere TRIANGLE studie uitgevoerd bij I89 volwassenen met epilepsie en een VB. In deze studie werden de stemming en angstklachten met behulp van de Nederlandstalige Anxiety Depression and Mood Scale in kaart gebracht. Bij 21,7\% van de mensen met epilepsie en een VB werd een verhoogde score op depressieve kenmerken vastgesteld, hetgeen overeenkomt met de reguliere bevolking. Het voorkomen van angst is met $\mathrm{I} 2,7 \%$ echter minder uitgesproken dan voor mensen met alleen epilepsie. Psychiatrische comorbiditeit leek vaker voor te komen bij patiënten met een focale epilepsie dan bij patiënten met een gegeneraliseerde vorm van epilepsie. Bijzonder genoeg kwamen deze verschijnselen juist minder vaak voor bij patiënten met een hoge aanvalsfrequentie, zelfs wanneer er in de analyses werd gecorrigeerd voor het gebruik van stemmingstabiliserende anti-epileptica.

\section{Therapeutische overwegingen}

In het proefschrift wordt het voorschrijfgedrag van Nederlandse artsen vergeleken met het voorschrijfgedrag in een Engels centrum ${ }^{2}$. Een belangrijke uitkomst is dat het gebruik van twee of minder anti-epileptica in de populatie van mensen met een VB eerder uitzondering is dan regel. Verder viel op dat valproaat, zowel in de Nederlandse als

\footnotetext{
${ }^{1}$ Promotor: Prof. dr. A.P. Aldenkamp, co-promotores: dr. H.J. Schelhaas en dr.J.G.M. Hendriksen.

${ }^{2}$ Cornwall Partnership NHS Foundation Trust, Bodmin, United Kingdom.
} 
Engelse studiepopulatie, het meest voorgeschreven antiepilepticum is. Als tweede anti-epilepticum geven de artsen in Engeland de voorkeur aan het niet-enzym-inducerende levetiracetam, terwijl in Nederland eerder voor carbamazepine wordt gekozen. Met het nieuwe anti-epilepticum perampanel werd geen van de deelnemers aan de onder- patiënt, over de epilepsie en de aanvallen, de verstandelijke beperking en eventuele bijkomende problematiek en in stap 02 van de etiologie. In stap o3 moet duidelijk worden waar rekening mee te houden bij de diagnostiek en behandeling, zoals context, taal en ontwikkelingsgeschiedenis van de patiënt. Stap o4 beschrijft het niveau van de verstan-

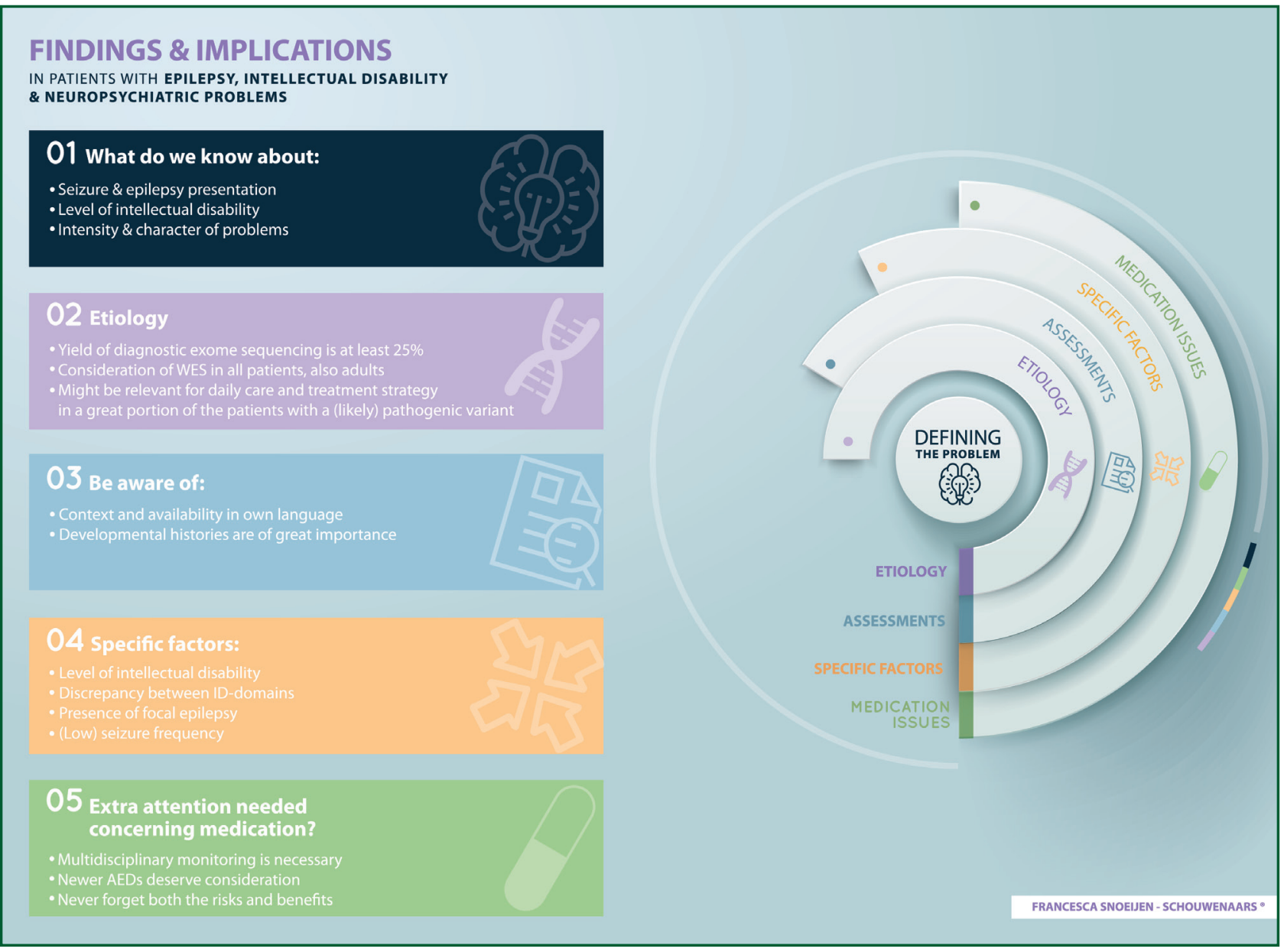

Figuur I In dit overzicht zijn de vijf stappen weergegeven waar een multidisciplinair team rekening mee moet houden bij de behandeling van mensen met epilepsie en een verstandelijke beperking.

zochte populatie aanvalsvrij en kwamen bijwerkingen in de vorm van gedrag- en stemmingsproblemen vaker voor. Bijwerkingen waren voor deze populatie de voornaamste reden voor het staken van perampanel. Verder bleek uit een evaluatieonderzoek dat bij patiënten met een nieuw gevonden mutatie in het $\mathrm{SCN} 1 \mathrm{~A}$ gen carbamazepine relatief gecontraïndiceerd is en dat valproaat en topiramaat veelal een eerste-keus-middel zijn. Opvallend was dat bij drie van de negen patiënten met een SCN1A mutatie, die soms al vele jaren carbamazepine gebruikten, de afbouw hiervan gepaard ging met een toename van de aanvalsfrequentie.

\section{Aambeveling voor behandeling}

In figuur I zijn de vijf stappen waar een multidisciplinair team rekening mee moet houden bij de behandeling van mensen met epilepsie en een VB weergegeven. In stap or wordt kennis genomen van de voorgeschiedenis van de delijke beperking en in stap 05 wordt er aandacht gegeven aan de medicatie. In het proefschrift wordt er voorts voor gepleit dat het starten, de opbouw en het stoppen van antiepileptica bij voorkeur plaatsvindt in multidisciplinair verband.

\section{Referenties}

Robertson J, Hatton C, Emerson E, Baines S (2015)

Prevalence of epilepsy among people with intellectual

disabilities: A systematic review. Seizure 2015;29:46-62.

Kerr M, Linehan C, Thompson R, Mula M, Gil-Nagal A,

Zuberi SM, Glynn M (2014) A White Paper on the

medical and social needs of people with epilepsy and

intellectual disability: The Task Force on Intellectual

Disabilities and Epilepsy of the International League

Against Epilepsy. Epilepsia 2014;55(12):1902-6. 